\title{
Rescue of Mesencephalic Dopaminergic Neurons in Culture by Low-Level Stimulation of Voltage-Gated Sodium Channels
}

\author{
Bénédicte Salthun-Lassalle, ${ }^{1}$ Etienne C. Hirsch, ${ }^{1}$ Jakob Wolfart, ${ }^{2}$ Merle Ruberg, ${ }^{1}$ and Patrick P. Michel ${ }^{1}$ \\ ${ }^{1}$ Institut National de la Santé et de la Recherche Médicale U289, Experimental Neurology and Therapeutics, Hôpital de la Salpêtrière, 75013 Paris, France, \\ and ${ }^{2}$ Integrative and Computational Neuroscience Unit, Centre National de la Recherche Scientifique Unité Propre de Recherche 2191, 91198 Gif-Yvette, France
}

We used a model system in which dopaminergic (DA) neurons from embryonic rat mesencephalon undergo spontaneous and selective degeneration as they develop in culture. Here, we show that DA cell loss can be prevented efficiently by low concentrations of the Na ${ }^{+}$ channel agonist veratridine. The survival promoting effect of veratridine was reproduced by, but independent of, glial cell line-derived neurotrophic factor. Neuroprotection by veratridine was exquisitely specific to DA neurons, short-lived after withdrawal, and abolished by tetrodotoxin, indicating that activation of voltage-gated $\mathrm{Na}^{+}$channels was crucially involved. Calcium measurements showed that veratridine-induced $\mathrm{Na}^{+}$influx was necessary to maintain intracellular $\mathrm{Ca}^{2+}$ within a neuroprotective range through the stimulation of low-voltage activated T-type calcium channels, a mechanism that was distinct from that elicited by high $\mathrm{K}^{+}$-evoked depolarization. Interestingly, increasing neuronal excitability by treatment with apamin, an inhibitor of $\mathrm{Ca}^{2+}$-activated $\mathrm{K}^{+}$channels, or with ouabain, a blocker of the $\mathrm{Na}^{+} / \mathrm{K}^{+}$-ATPase pump, was also neuroprotective by a mechanism involving T-type calcium channel activation. These results support the idea that mesencephalic DA neurons depend primarily on excitatory input for their survival during development.

Key words: channel; dopaminergic; excitability; GDNF; sodium; trophic

\section{Introduction}

The dopaminergic (DA) neurons from the nigrostriatal pathway are critically involved in the control of voluntary movements (DeLong, 1990; Grillner and Mercuri, 2002). Thus, their loss in Parkinson disease and related disorders leads to profoundly disabling motor abnormalities (Agid, 1991). The identification of signals and factors that regulate the differentiation, survival, and function of these neurons is therefore of interest, because it might not only provide a better understanding of the pathophysiological mechanisms of these diseases but also help to develop new strategies to halt their progression.

DA neurons possess intrinsic membrane properties that allow them to discharge in vivo either in a single-spike pacemaker mode or in a burst-firing pattern (Sanghera et al., 1984; Kita et al., 1986). These electrophysiological characteristics allow them to optimize the release of dopamine in terminal fields (Gonon and Buda, 1985). However, there is also evidence indicating that the electrical activity of DA neurons might serve to control their survival during development and possibly in the adult brain: (1) a mutation in the gene encoding the inwardly rectifying $\mathrm{K}^{+}$chan-

Received Dec. 23, 2003; revised March 22, 2004; accepted May 17, 2004.

This work was supported by Institut National de la Santé et de la Recherche Médicale and Centre National de la Recherche Scientifique. B.S.-L. was supported by a fellowship from Ministère de la Recherche et de la Technologie, and P.P.M. was supported by Pierre Fabre Research Center (Castres, France). $\alpha$-SCTX and TTX were given generously by B. Zalc.

Correspondence should be addressed to PatrickP. Michel, Bātiment Pharmacie, Hôpital de la Sal pêtrière, 47 bd de I'Hôpital, 75013, Paris, France. E-mail: ppmichel@ccr.jussieu.fr.

DOI:10.1523/JNEUROSCI.5668-03.2004

Copyright $\odot 2004$ Society for Neuroscience $\quad$ 0270-6474/04/245922-09\$15.00/0 nel GIRK2 (G-protein-gated inwardly rectifying $\mathrm{K}^{+}$channel 2) causes a selective loss of DA neurons in the substantia nigra of the weaver mouse (Patil et al., 1995); (2) glial cell line-derived neurotrophic factor (GDNF), a trophic factor that prevents DA neuronal death during development (Oo et al., 2003) and rescues injured DA neurons in adult animals (Choi-Lundberg et al., 1997), can also enhance the excitability of these neurons (Yang et al., 2001; Wang et al., 2003); (3) the pacemaker frequency of DA neurons that degenerate in Parkinson disease is generally lower than in those that survive (Neuhoff et al., 2002); and (4) the expression of tyrosine hydroxylase $(\mathrm{TH})$, which is augmented by increased electrical activity (Nagamoto-Combs et al., 1997), is downregulated in sick but still viable DA neurons in Parkinson disease (Hirsch et al., 1988).

We showed previously that depolarization by elevation of extracellular $\mathrm{K}^{+}\left(\left[\mathrm{K}^{+}\right]_{\mathrm{o}}\right)$ was efficient in preventing DA cell demise in a culture model in which the death of these neurons occurs spontaneously through a mechanism that is dependent on glial cells (Douhou et al., 2001; Mourlevat et al., 2003). However, elevated $\left[\mathrm{K}^{+}\right]_{\mathrm{o}}$ models neuronal depolarization imperfectly. Indeed, $\left[\mathrm{K}^{+}\right]_{\mathrm{o}}$ reaches depolarizing concentrations in vivo only during anoxic or ischemic episodes (Obrenovitch and Zilkha, 1995; Rytter et al., 2003). Furthermore, high $\left[\mathrm{K}^{+}\right]_{\mathrm{o}}$ stimulates glutamate release by reverse operation of glutamate transporters (Rossi et al., 2000), which generates excitotoxic stress counteracting the protective action of the depolarizing treatment in vitro (Douhou et al., 2001).

In the present study, we used the alkaloid veratridine, an ago- 
nist of voltage-gated $\mathrm{Na}^{+}$channels (Ulbricht, 1998), to depolarize the neurons without raising $\left[\mathrm{K}^{+}\right]_{\mathrm{o}}$. More specifically, we aimed at: (1) evaluating the neuroprotective potential of veratridine in comparison with that of elevated $\mathrm{K}^{+}$; (2) understanding the underlying mechanism and establishing whether it was shared with or related to that of GDNF; and (3) determining whether an increase in DA cell survival could also be achieved by other means than a direct activation of voltage-gated sodium channels in low $\mathrm{K}^{+}$conditions.

\section{Materials and Methods}

Mesencephalic cell cultures. Animals were treated in accordance with the Guide for the Care and Use of Laboratory Animals (National Institutes of Health, Bethesda, MD), the European Directive $N^{\circ} 86 / 609$, and the guidelines of the local institutional animal care and use committee. Cultures of postmitotic DA neurons were prepared from the ventral mesencephalon of embryonic day 15.5 (E15.5) Wistar rat embryos (Elevage Janvier, Le Genest St. Isle, France) as described previously (Michel and Agid, 1996). After dissection, pieces of mesencephalic tissue were dissociated mechanically with no enzymatic treatment using a Gilson Pipetman set to $900 \mu \mathrm{l}$ and plated onto polyethylenimine $(1 \mathrm{mg} / \mathrm{ml}$; Sigma-RBI-Aldrich, St. Quentin Fallavier, France)-coated 24-well culture plates. Cells plated at a density of $1.5-2.0 \times 10^{5} / \mathrm{cm}^{2}$ were then maintained at $37^{\circ} \mathrm{C}$ in a humidified incubator with a $5 \% \mathrm{CO}_{2}$ atmosphere using $500 \mu \mathrm{l}$ of $\mathrm{N} 5$ culture medium (Kawamoto and Barrett, 1986) supplemented with $5 \mathrm{~mm}$ glucose, $5 \%$ horse serum, and $0.5 \%$ fetal bovine serum, except for the first $3 \mathrm{~d}$ when $2.5 \%$ fetal bovine serum was used to enhance cell attachment. Cells were fed daily by replacing $350 \mu \mathrm{l}$ of the culture medium. Pharmacological reagents were obtained from Sigma-RBI-Aldrich. GDNF was purchased from AbCys SA (Paris, France) and the anti-GDNF neutralizing antibody (AB212 NA) from R \& D Systems Europe (Lille, France). Stock solutions of veratridine (50 mM) and flunarizine $(10 \mathrm{~mm})$ were prepared in pure ethyl alcohol. Nifedipine was prepared in dimethylsulfoxide at $10 \mathrm{~mm}$. Other pharmacological agents were diluted in sterile distilled water.

Quantification of neuronal survival. The survival of DA neurons was quantified by counting the number of cells labeled with an antibody against TH, as described previously (Michel et al., 1997). Briefly, the cultures were fixed with $4 \%$ formaldehyde in PBS for $15 \mathrm{~min}$. Cells were washed three times with PBS and then incubated $24 \mathrm{hr}$ at $4^{\circ} \mathrm{C}$ with a monoclonal anti-TH antibody (Diasorin, Stillwater, MN) diluted 1:1000 in PBS containing $0.2 \%$ Triton X-100. Subsequent incubations were performed at room temperature with a secondary biotinylated anti-mouse IgG (1:200 in PBS; Amersham Biosciences, Piscataway, NJ) followed by amplification with a preformed avidin-biotinylated horseradish peroxidase complex (Vectastain, AbCys SA). The peroxidase was revealed by incubation with the chromogen diaminobenzidine (DAB; $1 \mathrm{mg} / \mathrm{ml})$ in $0.006 \%$ hydrogen peroxide $\left(\mathrm{H}_{2} \mathrm{O}_{2}\right)$. When the intercalating agent 4,6diamidino-2-phenylindole (DAPI; $1 \mu \mathrm{g} / \mathrm{ml}$ in PBS) was used for the detection of the nuclear chromatin in DA neurons, the TH antibody was revealed by an anti-mouse IgG cyanin 3 (Cy3) conjugate (1:500; SigmaRBI-Aldrich). All neurons, regardless of their neurotransmitter phenotype, were identified by labeling microtubule-associated protein-2 (MAP-2) with a monoclonal antibody (AP-20; Sigma) diluted 1:100 in PBS using DAB as the chromogen.

Measurement of neurotransmitter uptake. The functional integrity of DA neurons was evaluated by their ability to take up DA by active transport (Douhou et al., 2001). Uptake was initiated by addition of $50 \mathrm{~nm}$ $\left[{ }^{3} \mathrm{H}\right]-\mathrm{DA}$ (Amersham Biosciences; $40 \mathrm{Ci} / \mathrm{mmol}$ ) to cultures preincubated for $10 \mathrm{~min}$ in $500 \mu \mathrm{l}$ of PBS containing $5 \mathrm{~mm}$ glucose and $100 \mu \mathrm{M}$ ascorbic acid. It was terminated after $15 \mathrm{~min}$ by two rapid washes with cold PBS. Cells were scraped off the culture wells, and the tritium taken up counted by liquid scintillation spectrometry. The uptake of $\left[{ }^{3} \mathrm{H}\right]-\mathrm{DA}$ was also visualized by microautoradiography (Troadec et al., 2002). In this case, the incubation time was prolonged to $30 \mathrm{~min}$, and $\left[{ }^{3} \mathrm{H}\right]$-DA was used at $100 \mathrm{~nm}$ to improve detection. The cultures were then fixed with a mixture of glutaraldehyde/formaldehyde $(0.5: 4 \%)$ and dehydrated with ethanol. Incorporation of $\left[{ }^{3} \mathrm{H}\right]-\mathrm{DA}$ was detected with the Hypercoat LM-1 emulsion (Amersham Biosciences) after an exposure of 7-10 d in the dark at $4^{\circ} \mathrm{C}$. In both paradigms, blank values were obtained in the presence of $10 \mu \mathrm{M}$ GBR-12,909 (Sigma). GABA uptake was measured as described previously (Michel et al., 1999) at $37^{\circ} \mathrm{C}$ with $50 \mathrm{~nm}\left[{ }^{3} \mathrm{H}\right]$-GABA (Amersham Biosciences; $85 \mathrm{Ci} / \mathrm{mmol}$ ) using an incubation time of $3 \mathrm{~min}$. Blank values were obtained at $4^{\circ} \mathrm{C}$. Serotonin $(5-\mathrm{HT})$ uptake was estimated after treatment of the cultures with $20 \mathrm{~nm}\left[{ }^{3} \mathrm{H}\right]-5$-HT (Amersham Biosciences; $120 \mathrm{Ci} / \mathrm{mmol}$ ) for $15 \mathrm{~min}$. Blank values were determined in the presence of $3 \mu \mathrm{M}$ citalopram (Lundbeck, Copenhagen, Denmark). Note that the concentrations of the three neurotransmitters were below the $K_{\mathrm{m}}$ values of their transporters to be within the linear portion of the uptake time course (Michel et al., 1990).

Uptake of $\left[{ }^{3} \mathrm{H}\right]$-methyl-thymidine. $\left[{ }^{3} \mathrm{H}\right]$-Methyl-thymidine, a marker of DNA synthesis, was used to label proliferating cells as described previously (Mourlevat et al., 2003). Mesencephalic cultures maintained for $6 \mathrm{~d}$ in vitro (DIV) in the presence of test treatments were exposed to $1 \mu \mathrm{Ci}$ $\left[{ }^{3} \mathrm{H}\right]$-methyl-thymidine (Amersham Biosciences; $40 \mathrm{Ci} / \mathrm{mmol}$ ) for $3 \mathrm{hr}$ at $37^{\circ} \mathrm{C}$ in serum-free $\mathrm{N} 5$ medium supplemented with $5 \mathrm{~mm}$ glucose. After three rapid washes, the cells were allowed to recover for $1 \mathrm{hr}$ in the same culture medium to remove unincorporated radioactivity. Finally, the cultures were fixed in $4 \%$ formaldehyde for $15 \mathrm{~min}$. Positive nuclei were visualized with Hypercoat LM-1 emulsion (Amersham Biosciences) after $4 \mathrm{~d}$ of exposition at $4^{\circ} \mathrm{C}$.

Measurements of intracellular calcium levels. Cytoplasmic-free calcium levels were measured in individual neurons using Calcium Green-1-AM (Molecular Probes, Eugene, OR) as described previously (Douhou et al., 2001). Briefly, cultures grown for $7 \mathrm{~d}$ were incubated with $10 \mu \mathrm{M}$ Calcium Green-1-AM for $30 \mathrm{~min}$ at $37^{\circ} \mathrm{C}$ and then washed twice with serum-free glucose-supplemented N5 medium to remove the indicator in excess and left to recover for $30 \mathrm{~min}$ before assessment. The fluorescent signal (excitation, $480 \mathrm{~nm}$; emission, $510 \mathrm{~nm}$ ) was quantified using the Simple-PCI software from C-Imaging Systems and a Nikon (Tokyo, Japan) TE-300 inverted microscope equipped with an ORCA-ER digital camera from Hamamatsu (Bridgewater, NJ). Fluorescent images of randomly chosen fields (six to eight in each culture condition) were acquired with a $63 \times$ fluorescent objective. The average pixel intensity over the surface of each cell body was determined under the different experimental conditions. Background fluorescence was subtracted from raw data, and the results were expressed as percentage of mean fluorescence intensity per cell in control conditions. A minimum of 60 cells was analyzed under each test condition.

Reverse transcription and PCR. Total RNA from mesencephalic cultures was isolated with RNeasy Mini kit (Qiagen, Courtaboeuf, France). Three types of cultures were used, mixed cultures containing neuronal and glial cells, pure neuronal cultures where glial cells were eliminated by treatment with $3 \mu \mathrm{M}$ araC, and pure astrocyte cultures. Total RNA from adult rat mesencephalon was extracted with the RNAble solution (Eurobio, Les Ulis, France). First strand cDNA was synthesized from $1 \mu \mathrm{g}$ of total RNA using the RT kit (Qiagen). To analyze the expression of the subunits $\alpha 1 \mathrm{G}$ and $\alpha 1 \mathrm{H}$ of the T-type calcium channels, transcripts were amplified by PCR under the following conditions: 35 cycles $(\alpha 1 \mathrm{G})$ or 30 cycles $(\alpha 1 \mathrm{H})$ of $94^{\circ} \mathrm{C}$ for $30 \mathrm{sec}, 60^{\circ} \mathrm{C}$ for $30 \mathrm{sec}$, and $72^{\circ} \mathrm{C}$ for 1 min with $2 \mu \mathrm{l}$ of the reverse transcription mixture. The primers used were: rat $\alpha 1 \mathrm{G}$, forward (5'-GGAGCCAGTCCGTTGCCAG-3') and reverse (5'AGGAGCAGGAGAGCCAGAGT-3') (GenBank accession number AF027984); rat $\alpha 1 \mathrm{H}$, forward (5' -GCCTCCCTCGTGGTGATTCAG-3') and reverse (5' -TGAGCCCAACAGCCTGGAATG-3') (GenBank accession number AF290213). The PCR products were visualized by electrophoresis in a $2 \%$ agarose gel containing $0.1 \mathrm{mg} / \mathrm{ml}$ ethidium bromure.

Statistical analysis. Simple comparisons between two groups were performed with Student's $t$ test. Multiple comparisons against a single reference group were made by one-way ANOVA followed by Dunnett's test. When all pairwise comparisons were made, the Student-Newman-Keuls test was used. SEM values were derived from at least three independent experiments.

\section{Results}

Sodium influx through voltage-gated channels promotes the survival of mesencephalic DA neurons

Mesencephalic DA neurons degenerate spontaneously and progressively when maintained in N5 culture medium supplemented 


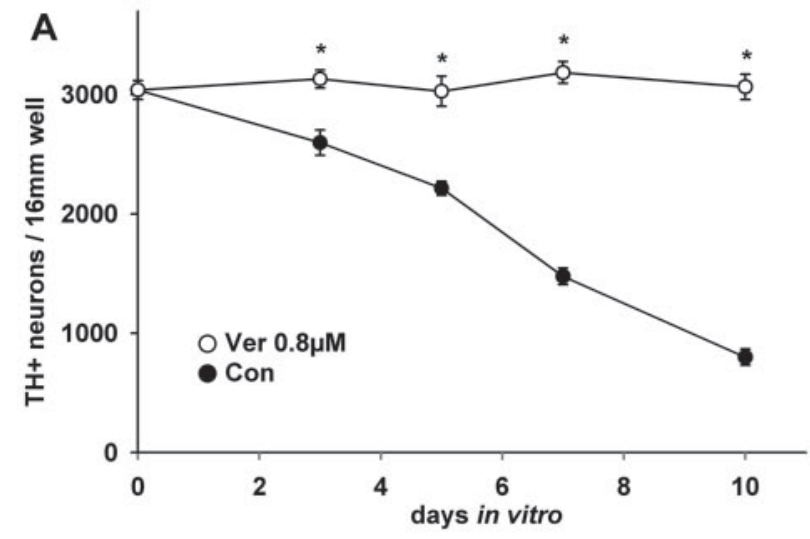

B
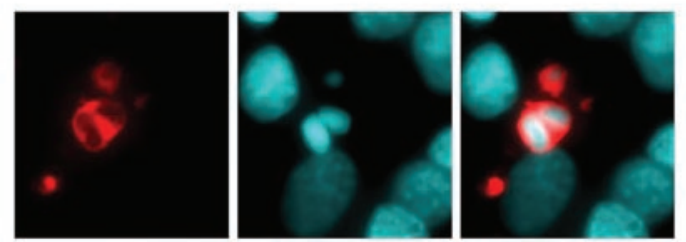

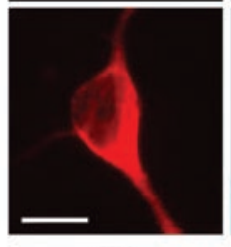

TH

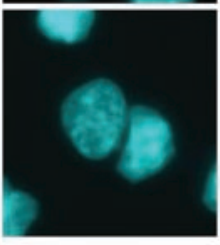

DAPI

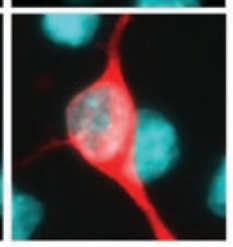

merge
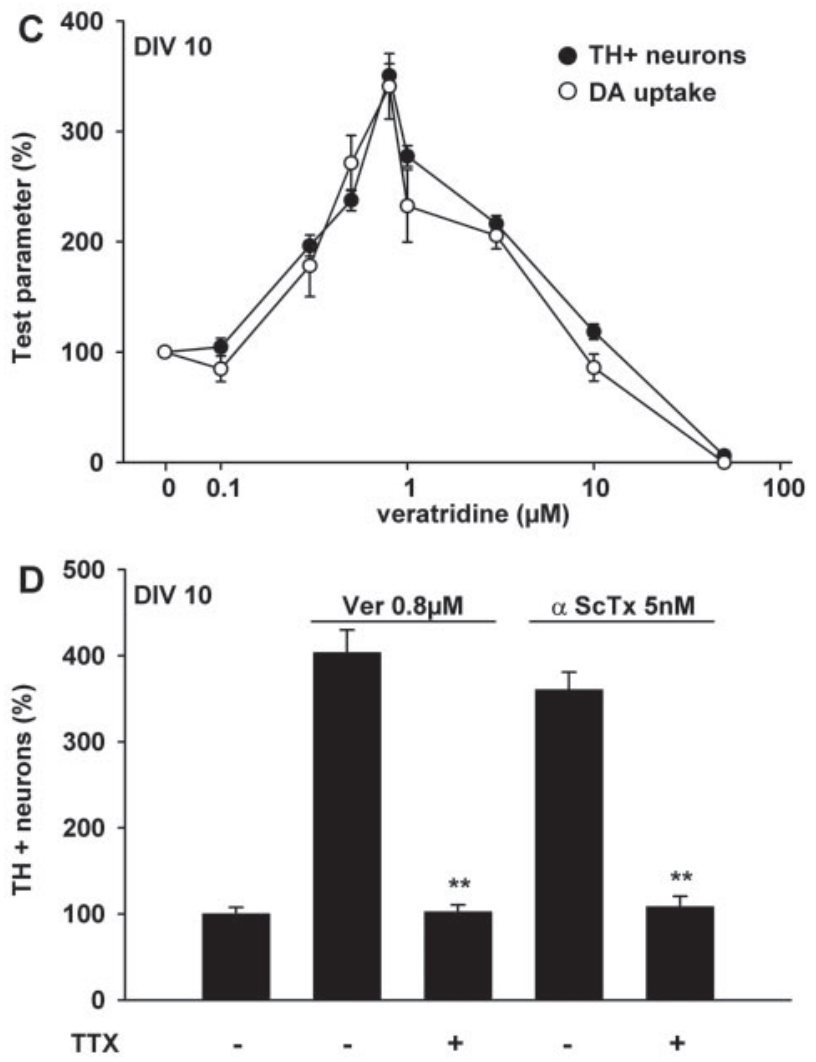

Figure 1. Protection of DA neurons in mesencephalic cultures by chronic activation of voltage-gated sodium channels. $A$, Number of $\mathrm{TH}^{+}$neurons in veratridine (Ver)-treated (0.8 $\mu \mathrm{m}$ ) and in control (Con) cultures as a function of the age of the cultures. $B$, Detection of $\mathrm{TH}$ and nuclear chromatin using a Cy3 conjugate (red) and the intercalating agent DAPI (blue), respectively. Degenerating (top panel) and healthy (bottom panel) $\mathrm{TH}^{+}$neurons from a control culture are shown. Note the presence of a fragmented and condensed nuclear chromatin in the
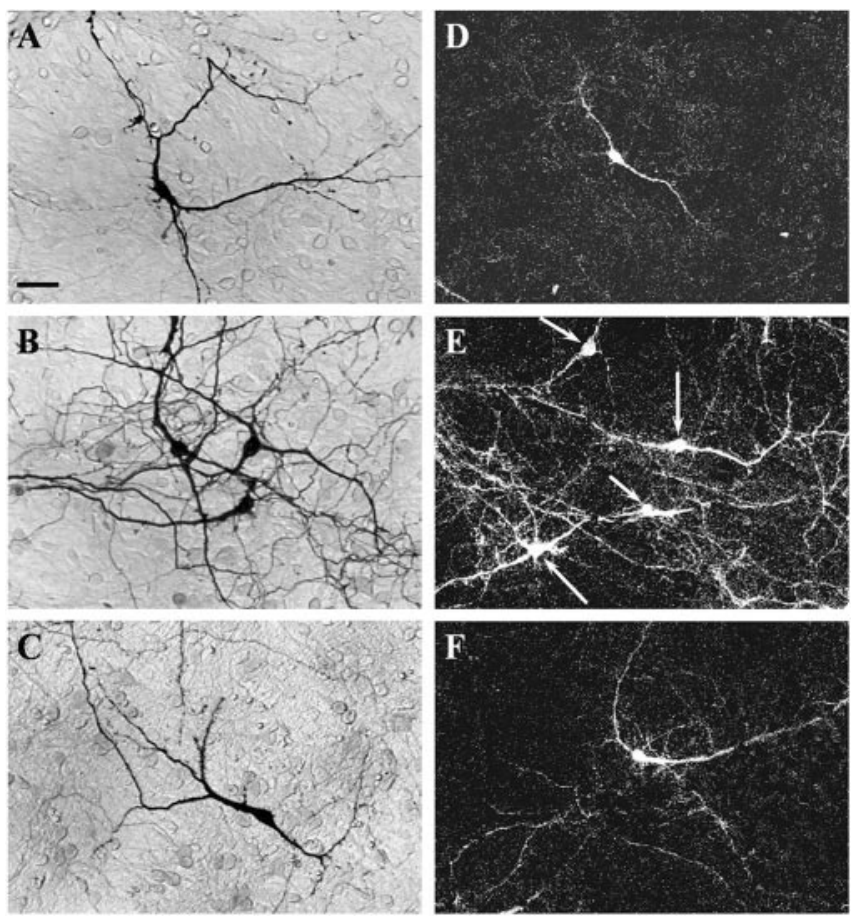

Figure 2. Illustration of the effects of a chronic treatment with veratridine on DA neurons. $A-F$, DA neurons were visualized by $\mathrm{TH}$ immunocytochemistry $(A-C)$ and microautoradiographic detection of $\left[{ }^{3} \mathrm{H}\right]-\mathrm{DA}(D-F)$ in 10 DIV mesencephalic cultures. Control cultures $(A, D)$ and cultures chronically treated by $0.8 \mu \mathrm{m}$ veratridine in the absence $(B, E)$ or in the presence $(C$, F) of $\left.50 \mathrm{~nm} \mathrm{TTX.} \mathrm{White} \mathrm{arrows} \mathrm{point} \mathrm{to} \mathrm{[}{ }^{3} \mathrm{H}\right]-\mathrm{DA}{ }^{+}$cell bodies in $E$. Scale bar, $40 \mu \mathrm{m}$.

with serum proteins, whereas other types of neurons survive (Michel and Agid, 1996; Douhou et al., 2001). In the present study, we found that $50 \%$ of $\mathrm{TH}^{+}$neurons had disappeared at 7 DIV and $>70 \%$ at 10 DIV (Fig. $1 A$ ). Careful examination of these cultures revealed the constant presence of a small but significant population of $\mathrm{TH}^{+}$neurons showing clear signs of degeneration. These neurons had rounded or shrunken cell bodies with neurites that were either swollen or entirely disintegrated. They also presented a chromatin that was condensed and fragmented (Fig. $1 B)$, suggesting that an ongoing apoptotic process was taking place. When low concentrations of the voltage-gated sodium $\left(\mathrm{Na}^{+}\right)$channel agonist veratridine were applied chronically to the cultures, the loss of $\mathrm{TH}^{+}$neurons was reduced in a dosedependent manner. The neuroprotective effects of veratridine, already significant at $0.3 \mu \mathrm{M}$, increased gradually up to $0.8-1 \mu \mathrm{M}$ before declining progressively up to $10 \mu \mathrm{M}$. Above $10 \mu \mathrm{M}$, veratridine had an adverse effect, exacerbating the spontaneous demise of DA cells (Fig. 1C). Counts of $\mathrm{TH}^{+}$neurons performed at different stages of maturation of the cultures indicate that veratridine acted most likely by preventing DA cell loss (Fig. $1 \mathrm{~A}$ ). Consistent with this view, the number of apoptotic $\mathrm{TH}^{+}$cell bodies was also greatly reduced by veratridine treatment. For instance, at $7 \mathrm{DIV}$, we counted $440 \pm 80$ and $116 \pm 38 \mathrm{TH}^{+}$

\footnotetext{
dying DA neuron. Scale bar, $10 \mu \mathrm{m}$. C, Number of $\mathrm{TH}^{+}$neurons and quantification of $\left[{ }^{3} \mathrm{H}\right]-\mathrm{DA}$ uptake as a function of the concentration of veratridine $(0-50 \mu \mathrm{M})$. Actual control values for the number of $\mathrm{TH}^{+}$neurons and the uptake of $\left[{ }^{3} \mathrm{H}\right]$-DA expressed per $16 \mathrm{~mm}$ culture well were 800 and $33 \mathrm{fmol} / \mathrm{min}$, respectively. D, Number of $\mathrm{TH}^{+}$neurons in cultures treated with veratridine $(0.8 \mu \mathrm{M})$ or $\alpha$-ScTX $(5 \mathrm{~nm})$ in the presence or the absence of $50 \mathrm{~nm} \mathrm{TTX.}{ }^{*} p<0.05$, different from corresponding aged-matched control cultures. ${ }^{* *} p<0.05$, different from cultures treated with the corresponding sodium channel agonist alone.
} 

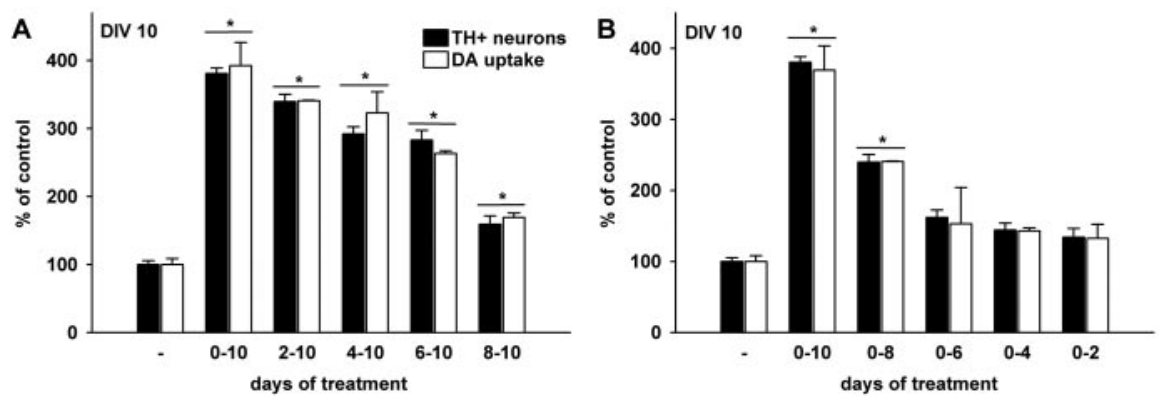

Figure 3. The effects of veratridine depend on the length of the treatment and the time at which it is initiated. Mesencephalic cultures exposed to $0.8 \mu \mathrm{m}$ of veratridine for various time intervals between 0 and 10 DIV were then assessed for TH immunocytochemistry and $\left[{ }^{3} \mathrm{H}\right]$-DA uptake at 10 DIV. $A$, Veratridine-induced depolarization still increased survival and DA uptake when the treatment was postponed after plating. $B$, The effects of veratridine were short-lived after treatment was stopped. ${ }^{*} p<0.05$, different from corresponding control cultures.
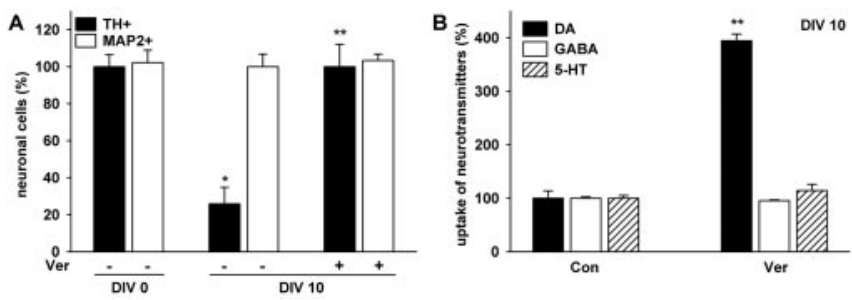

Figure 4. Trophic effects of veratridine are specific to DA neurons. A, Treatment of mesencephalic cultures with veratridine (Ver $0.8 \mu \mathrm{m}$ ) between 0 and 10 DIV promoted the survival of $\mathrm{TH}^{+}$neuronal cells but had no effect on the number of MAP- $2^{+}$neurons. $B$, The same treatment strongly promoted the accumulation of $\left[{ }^{3} \mathrm{H}\right]-\mathrm{DA}$ but had no effect on the uptake of $\left[{ }^{3} \mathrm{H}\right]-\mathrm{GABA}$ and $\left[{ }^{3} \mathrm{H}\right]-5-\mathrm{HT}$. Control values for the number of $\mathrm{TH}^{+}$and $\mathrm{MAP}-2^{+}$neurons per well at 0 DIV were 2745 and $380 \times 10^{3}$. Control values at 10 DIV for the uptakes of [ $\left.{ }^{3} \mathrm{H}\right]-\mathrm{DA}$, [ ${ }^{3} \mathrm{H}$ ]-GABA, and [ $\left.{ }^{3} \mathrm{H}\right]-5$-HT were $35 \mathrm{fmol} / \mathrm{min} /$ well, $1.75 \mathrm{pmol} / \mathrm{min} /$ well, and $65 \mathrm{fmol} / \mathrm{min} /$ well, respectively. ${ }^{*} p<0.05$, different from cultures at 0 DIV; ${ }^{* *} p<0.05$, different from corresponding control cultures at $10 \mathrm{DIV}$.

apoptotic cell bodies per $16 \mathrm{~mm}$ culture well in control and veratridine $(0.8 \mu \mathrm{M})$-treated cultures, respectively. $\mathrm{TH}^{+}$neurons rescued by veratridine had elaborate neuritic processes (Fig. $2 B$ ). They also appeared healthy and functional because they efficiently accumulated $\left[{ }^{3} \mathrm{H}\right]$-DA via active transport (Figs. $1 C, 2 E$ ). However, the treatment with veratridine did not modify the rate of the uptake per neuron, estimated to 41 and $4210^{-3} \mathrm{fmol} / \mathrm{min}$ in control and veratridine-treated cultures, respectively.

The $\alpha$-scorpion toxin ( $\alpha$-ScTx), a polypeptide that functions as an $\mathrm{Na}^{+}$channel agonist (Jover et al., 1988), mimicked the survival promoting effect of veratridine when used at a concentration of $5 \mathrm{~nm}$ (Fig. $1 D$ ). The trophic activities of both veratridine and the $\alpha$-ScTx were abolished when tetrodotoxin (TTX), a fugu fish toxin that acts as a noncompetitive antagonist of voltage-gated sodium channels (Catterall, 1980), was added to the cultures (Figs. $1 D, 2 C, F$ ). This demonstrates that most of the DA neurons were dependent on sodium influx for their survival.

\section{Survival promotion of DA neurons by veratridine depends on} the duration of treatment

When the depolarizing treatment with an optimal concentration of veratridine was postponed after plating, the number of rescued $\mathrm{TH}^{+}$neurons diminished progressively (Fig. 3A). Cultures treated continuously for $10 \mathrm{~d}(0-10 \mathrm{DIV})$ with $0.8 \mu \mathrm{M}$ veratridine had $280 \%$ more $\mathrm{TH}^{+}$neurons than untreated cultures, whereas cultures only treated on days $8-10$ had $60 \%$ more. Conversely, the protective effect of veratridine was rapidly reversible if the depolarizing treatment was stopped prematurely and the cultures maintained in control medium up to 10 DIV (Fig. 3B). Characteristically, if veratridine was withdrawn at day 8 , only half as many neurons were saved $2 \mathrm{~d}$ later; if withdrawn at day 6 , there was no net increase in the number of $\mathrm{TH}^{+}$neurons at $10 \mathrm{DIV}$ (Fig. $3 B$ ). Results were comparable when the uptake of $\left[{ }^{3} \mathrm{H}\right]-\mathrm{DA}$ was used as an index of function and survival of DA neurons (Fig. $3 A, B$ ).

\section{Sodium influx promotes selectively the} survival of DA neurons

$\mathrm{TH}^{+}$cells represent $\sim 1-2 \%$ of the total number of neurons in the culture system used at the time of plating. We therefore wished to determine whether neuroprotective concentrations of veratridine also had an effect on the non-DA neurons, predominantly GABAergic (Lannuzel et al., 2002), and to lesser extent serotoninergic neurons (Casper et al., 1991). To this end, we labeled the entire population of neurons by MAP-2 immunostaining. Unlike what we observed for $\mathrm{TH}^{+}$neurons, there was no spontaneous loss of MAP-2 ${ }^{+}$neuronal cells between 0 and 10 DIV. Furthermore, veratridine treatment did not increase the number of these neurons during the same time period (Fig. 4A) or the uptake of tritiated GABA or 5-HT, functional markers of GABAergic and serotoninergic neurons, respectively (Fig. 4B).

Sodium influx does not act by reducing glial cell proliferation We know from previous studies that DA neurons can be rescued efficiently in this culture model by reducing the proliferation of astrocytes or their precursor cells with synthetic deoxynucleosides (Michel et al., 1997) or with purine derivatives acting as antimitotics (Michel et al., 1999; Mourlevat et al., 2003). Thus, the question arose as to whether veratridine protected $\mathrm{TH}^{+}$neurons indirectly through the repression of glial cell proliferation. As described previously, the reduction of dividing glial cells by the synthetic deoxynucleoside araC led to a robust increase in the number of $\mathrm{TH}^{+}$neurons counted at 10 DIV (Fig. 5A). A concomitant treatment with the natural competitor of ara-C, dCTP $(100 \mu \mathrm{M})$, prevented neuroprotection and restored glial cell proliferation, confirming that the antimitotic acted by causing cell cycle arrest. Unlike araC, veratridine $(0.8 \mu \mathrm{M})$ did not reduce the number of thymidine ${ }^{+}$nuclei (Fig. $5 B, C$ ), indicating that the alkaloid did not act via an antiproliferative mechanism.

\section{A rise in intracellular calcium levels mediates the trophic effect of veratridine}

It is well known that the sodium influx induced by veratridine leads secondarily to an elevation of intracellular calcium levels $\left(\left[\mathrm{Ca}^{2+}\right]_{\mathrm{i}}\right)$ via voltage-gated calcium channels (Meder et al., 1999; Fernandez Pereira and Giestal, 2000). We therefore studied the role of calcium in the trophic effect of veratridine. When the alkaloid was applied to the cultures at concentrations that promote optimal survival of DA neurons, we observed an increase in $\left[\mathrm{Ca}^{2+}\right]_{\mathrm{i}}$ of $\sim 40 \%$ above control levels. Increases of smaller or greater amplitude of $\left[\mathrm{Ca}^{2+}\right]_{i}$ produced by lower and higher concentrations of veratridine, respectively, were progressively less effective (Fig. 6), suggesting that DA cell survival was closely correlated to cytoplasmic calcium levels.

We next wished to understand the mechanisms linking DA cell survival to the increase in $\left[\mathrm{Ca}^{2+}\right]_{\mathrm{i}}$. As expected, the rise in 


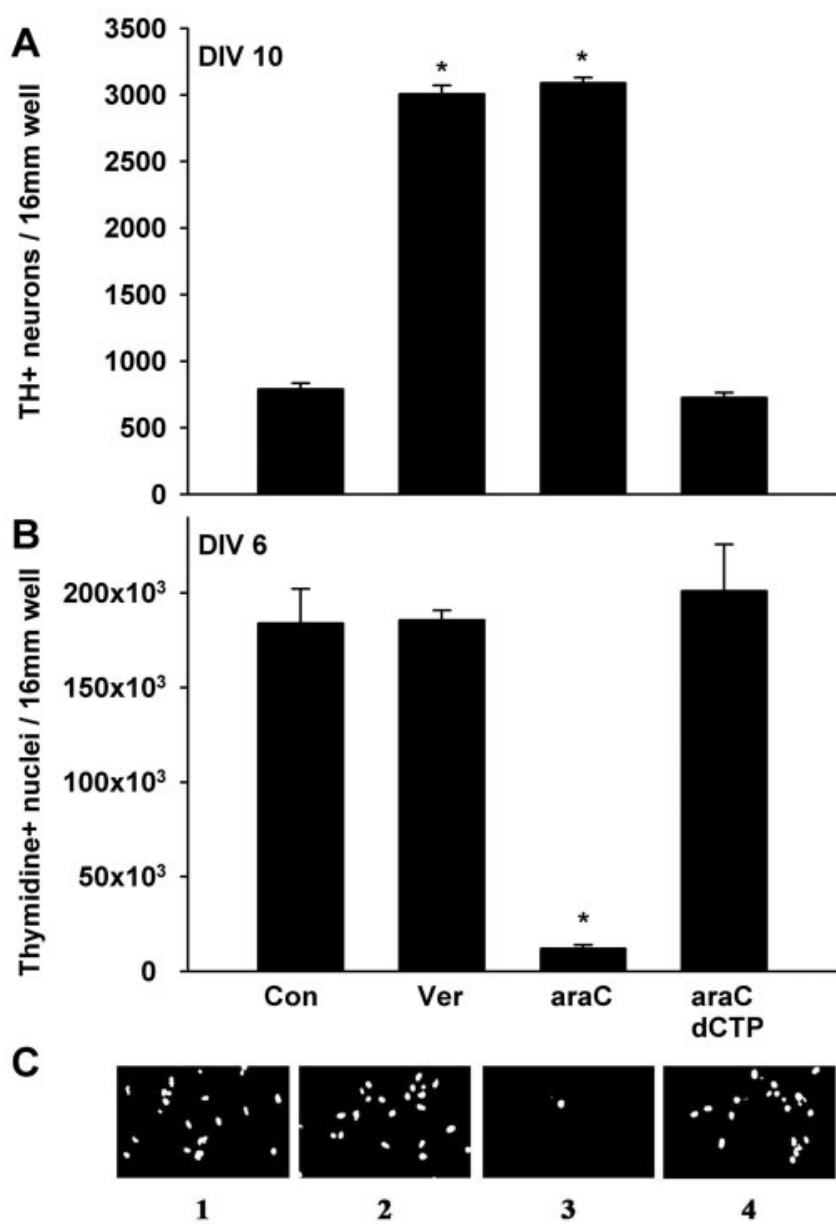

Figure 5. Veratridine-induced depolarization does not affect glial cell proliferation in mesencephalic cultures. $A$ shows the number of $\mathrm{TH}^{+}$neurons at $10 \mathrm{DIV}$, and $B$ shows the number of thymidine ${ }^{+}$nuclei at 6 DIV in mesencephalic cultures maintained in the presence of the following treatments: $\operatorname{Ver}(0.8 \mu \mathrm{m})$; $\operatorname{araC}(0.5 \mu \mathrm{M})$; araC plus dCTP $(100 \mu \mathrm{M})$. C, Visualization of the effects of the above treatments on the number of thymidine ${ }^{+}$nuclei $(1$, Con; 2, Ver; 3 , araC; 4 , araC plus d(TP). ${ }^{*} p<0.05$, different from corresponding control cultures.

$\left[\mathrm{Ca}^{2+}\right]_{\mathrm{i}}$ induced by veratridine $(0.8 \mu \mathrm{M})$ was consecutive to the activation of inward $\mathrm{Na}^{+}$currents. Indeed, the capacity of the alkaloid to promote DA cell survival and to raise $\left[\mathrm{Ca}^{2+}\right]_{\mathrm{i}}$ was abolished by treatment with the sodium channel blocker TTX (Fig. $7 A, B$, left panels). To further study the consequences of the rise in cytoplasmic calcium levels on DA neuron survival, we exposed veratridine-treated mesencephalic cultures to various voltage-gated calcium channel blockers. Flunarizine $(5 \mu \mathrm{M})$, an antagonist of low voltage-activated T-type calcium channels (Santi et al., 2002), not only prevented the increase in $\left[\mathrm{Ca}^{2+}\right]_{\mathrm{i}}$ but also abolished the effect of veratridine on the survival of $\mathrm{TH}^{+}$ cells (Fig. $7 A, B$, left panels). Flunarizine can also act as a neuroleptic by preferentially blocking D2 DA receptors (Ambrosio and Stefanini, 1991). We therefore compared its efficacy with that of a reference antagonist of this DA receptor subtype, sulpiride. Unlike flunarizine, sulpiride $\left(\begin{array}{ll}10 \mu \mathrm{M}\end{array}\right)$ did not prevent the veratridine-induced rise in $\left[\mathrm{Ca}^{2+}\right]_{\mathrm{i}}$ or its consequences on neuronal survival (Fig. $7 A, B$, left panels). Again, consistent with the implication of T-type calcium channels, the elevation in $\left[\mathrm{Ca}^{2+}\right]_{\mathrm{i}}$ produced by veratridine was also prevented by nickel (Fig. $7 C$, left), a blocker of this calcium channel subtype when used at a concentration of $100 \mu \mathrm{M}$ (Tritsch et al., 1998; Lee et al., 1999). We

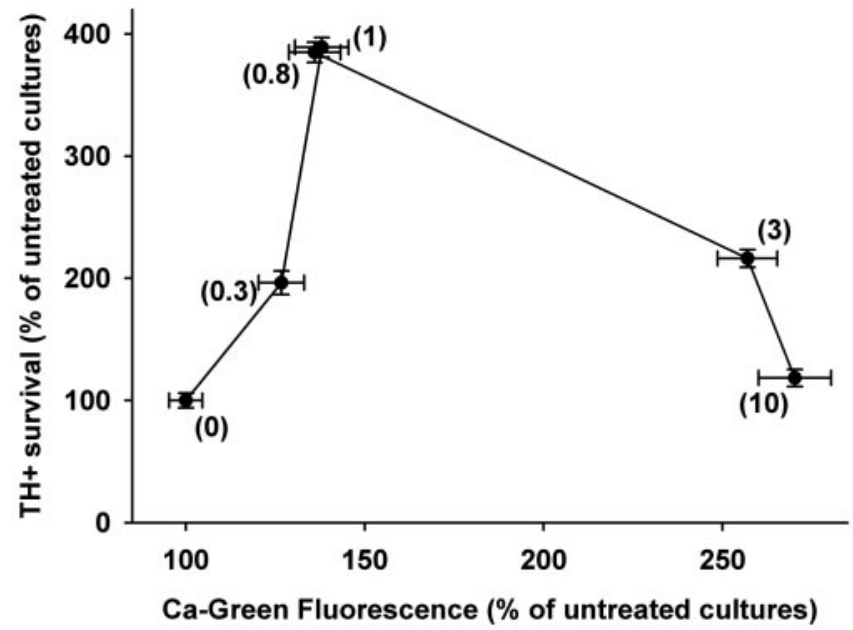

Figure 6. Survival of DA neurons plotted against Calcium-Green-1 fluorescence levels. Test concentrations of veratridine $(0-10 \mu \mathrm{m})$ are indicated in parentheses above each data point. Optimal survival of DA neurons occurs within a range of elevated $\left[\mathrm{Ca}^{2+}\right]_{i}$ corresponding to an increase of $\sim 40 \%$ above basal levels.

confirmed the presence of the $\alpha 1 \mathrm{H}$ and $\alpha 1 \mathrm{G}$ subunits of T-type calcium channels on neuronal cells in mesencephalic cultures by amplification of the corresponding transcripts by reverse transcriptase (RT)-PCR (Fig. 7C, right).

We know from previous studies that an increase in DA cell survival equivalent to that produced by $0.8 \mu \mathrm{M}$ veratridine can be obtained by applying depolarizing concentrations of $\mathrm{K}^{+}(30 \mathrm{mM})$ to mesencephalic cultures in the presence of NMDA or AMPA/ kainate receptor blockers (Douhou et al., 2001). Neuroprotection in this paradigm was also the result of a small rise in $\left[\mathrm{Ca}^{2+}\right]_{\mathrm{i}}$, but the mechanism underlying this effect was totally distinct from that of veratridine. Here, we show that the effects of a treatment combining elevated $\mathrm{K}^{+}(30 \mathrm{~mm})$ and (+)-5-methyl-10,11dihydro-5H-dibenzo $[\mathrm{a}, \mathrm{d}]$ cyclohepten-5,10-imine maleate (MK-801; $1 \mu \mathrm{M})$, a noncompetitive NMDA receptor antagonist, were resistant to TTX and flunarizine (Fig. $7 A, B$, right panels). However, they were abolished by the high threshold-activated L-type calcium channel antagonist nifedipine, which in turn was ineffective against veratridine (Fig. $7 A, B$, left panels). The effects of veratridine were also resistant to $\omega$-conotoxin, an inhibitor of the high threshold-activated N, P, and Q-type calcium channels (data not shown).

Apamin and ouabain partially mimic the effects of veratridine Next, we determined whether an increase in DA survival might also be produced by other means than a direct activation of voltage-gated sodium channels when $\left[\mathrm{K}^{+}\right]_{\mathrm{o}}$ was set at a normal concentration of $3 \mathrm{~mm}$. We therefore exposed our cultures to apamin and ouabain, toxins known to increase the excitability threshold of neuronal cells by blocking the $\mathrm{Ca}^{2+}$-activated $\mathrm{K}^{+}$ (SK) channels (Romey et al., 1984) and the $\mathrm{Na}^{+} / \mathrm{K}^{+}$-ATPase pump (Nelson et al., 2003), respectively. At an optimal concentration of $0.5 \mu \mathrm{M}$, apamin increased the survival of $\mathrm{TH}^{+}$neurons by $\sim 70 \%$ after $10 \mathrm{~d}$ of continuous treatment. The effect of apamin was potentiated by suboptimal concentrations of veratridine $(0.3 \mu \mathrm{M})$ and prevented by TTX and flunarizine (Fig. $8 \mathrm{~A})$. At an optimal concentration of $1 \mu \mathrm{M}$, ouabain afforded the same degree of protection as apamin. However, the survival promoting effect of ouabain was resistant to TTX and not additive to that produced by suboptimal concentrations of veratridine. It was 
A
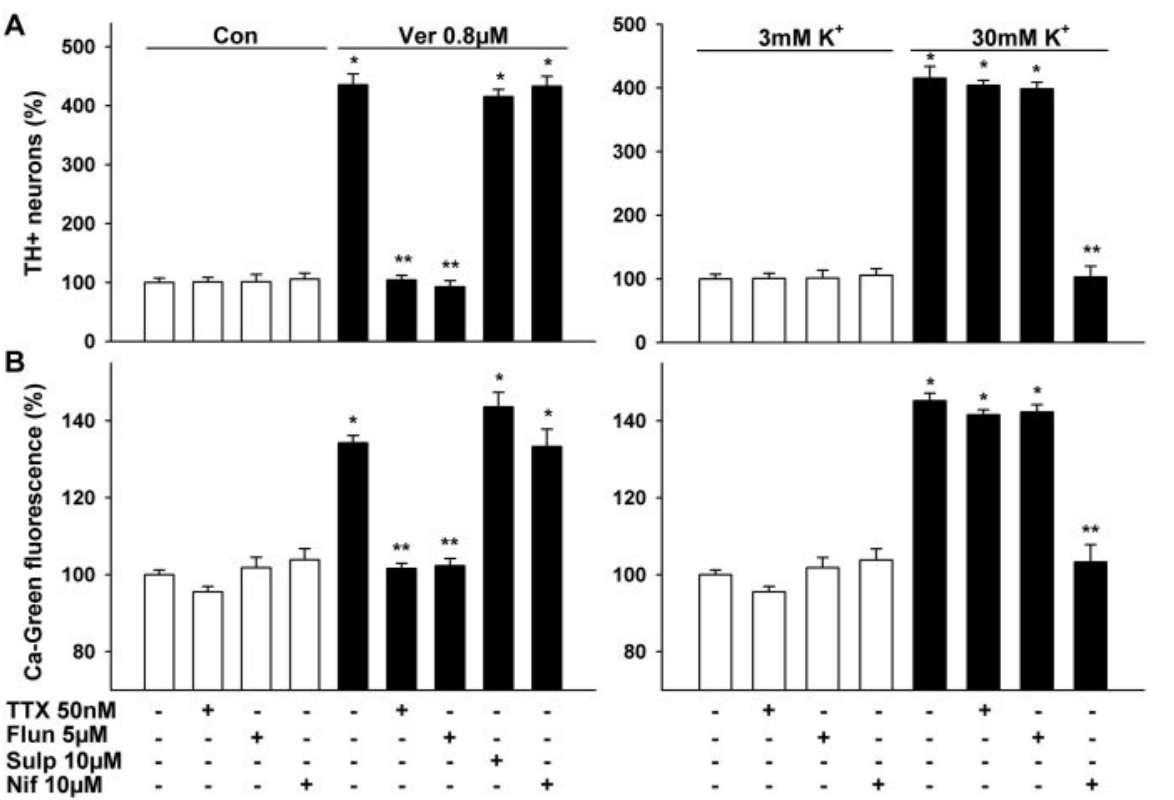

C

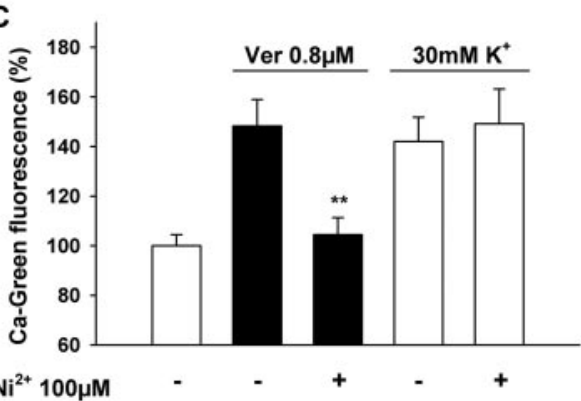

Figure 7. Role of T-type calcium channels in the survival promoting effects of veratridine on DA neurons. $A$, Number of $\mathrm{TH}^{+}$ neurons in mesencephalic cultures at 10 DIV. B, Calcium-Green-1 fluorescence levels at 7 DIV. Pharmacological treatments used to modulate the effects of veratridine-induced (Ver) (left panels) or high $\mathrm{K}^{+}$-induced (right panels) depolarization are indicated above. Flun, Flunarizine; Nif, nifedipine; Sulp, sulpiride. Trophic effects of veratridine and elevated $\mathrm{K}^{+}(30 \mathrm{~mm})$ are correlated with a moderate rise in $\left[\mathrm{Ca}^{2+}\right]_{\mathrm{j}}$. Note that $\mathrm{K}^{+}$-induced depolarization was performed in the presence of $1 \mu \mathrm{m}$ MK-801 to prevent secondary excitotoxic stress. C, Left, Modulation by $\mathrm{Ni}^{2+}$ of Calcium-Green-1 fluorescence levels in mesencephalic neurons exposed to veratridine or high $\mathrm{K}^{+}$. Right, RT-PCR products of T-type calcium channel $\alpha 1 \mathrm{H}$ and $\alpha 1 \mathrm{G}$ subunits were resolved by gel electrophoresis in parallel with a $100 \mathrm{bp}$ ladder as molecular weight marker. Detection was performed in pure neuronal (1), mixed glial/neuronal (2), pure astrocyte (3) cultures, and in mesencephalic tissue from adult rat brain (4); RT-PCR performed without RNA (5). ${ }^{*} p<0.05$, higher than corresponding untreated cultures; ${ }^{* *} p<0.05$, lower than corresponding cultures treated with veratridine or high $\mathrm{K}^{+}$alone.
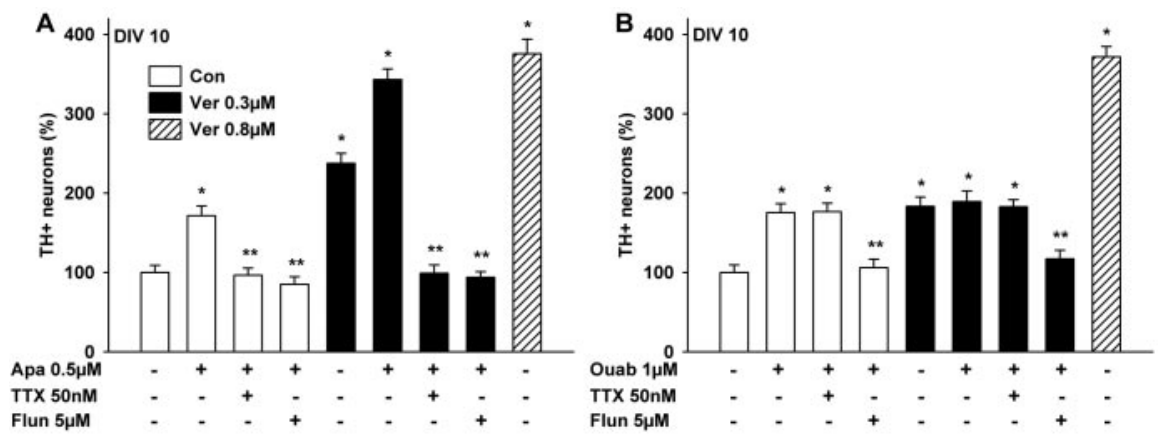

Figure 8. Comparison of the effects of veratridine with apamin or ouabain on mesencephalic DA neurons. $A$ shows the number of $\mathrm{TH}^{+}$cells in cultures treated with apamin (Apa) in the presence or the absence of veratridine (Ver). B shows the number of $\mathrm{TH}^{+}$ cells in cultures exposed to ouabain (Ouab) in the presence or the absence of veratridine. TTX and flunarizine were used to modulate the effects of the depolarizing treatments in $A$ and $B$. Concentrations of test compounds are indicated above. ${ }^{*} p<0.05$, higher than corresponding control cultures; ${ }^{* *} p<0.05$, lower than corresponding cultures depolarized with the same treatments. abolished, however, by flunarizine, indicating that T-type calcium channels were involved (Fig. 8B).

The effect of veratridine is reproduced by, but independent of, GDNF

We then compared the neuroprotective activity of veratridine to that of GDNF, the prototypical neurotrophic peptide for mesencephalic DA neurons (Lin et al., 1993). In the presence of optimal concentrations of GDNF $(10 \mathrm{ng} / \mathrm{ml})$ or veratridine $(0.8 \mu \mathrm{M})$, $\mathrm{TH}^{+}$neurons survived to the same extent (Fig. 9A). This suggested that the activation of voltage-gated sodium channels by veratridine might have increased DA cell survival by stimulating the production and subsequent release of GDNF into the culture medium. However, an anti-GDNF antibody (AB212 NA; $5 \mu \mathrm{g} / \mathrm{ml}$ ), which completely neutralized the trophic effect of the peptide, failed to reduce that of veratridine (Fig. $9 A$ ). Furthermore, the effect of GDNF did not require the activation of TTX-sensitive voltage-gated sodium channels or T-type calcium channels, because neither TTX nor flunarizine reduced its survival promoting activity (Fig. 9B).

\section{The neuroprotective effect of} veratridine is not mediated by other putative secreted factors

We also examined the possibility that a factor other than GDNF, secreted by glial or neuronal cells, mediated the trophic action of veratridine. Hence, we analyzed the survival of $\mathrm{TH}^{+}$cells maintained in a culture medium that had been conditioned previously by mesencephalic cultures exposed to $0.8 \mu \mathrm{M}$ veratridine. After $10 \mathrm{~d}$ of daily treatment, this medium afforded protection to DA neurons, but only because it contained veratridine, because its effect could be abolished by either TTX or flunarizine (Fig. 9C).

\section{Discussion}

The present study demonstrates that lowlevel activation of voltage-gated $\mathrm{Na}^{+}$channels by the alkaloid veratridine affords longterm neuroprotection in a model system in which mesencephalic DA neurons undergo spontaneous and selective degeneration. Survival promotion of dopaminergic neurons by veratridine was reproduced by, but independent of, GDNF. It resulted secondarily from a small rise in $\left[\mathrm{Ca}^{2+}\right]_{i}$ via the activation of T-type calcium channels.

\section{Veratridine acts as a true}

neuroprotective factor for DA neurons Several mechanisms might account for the survival promoting effect of veratridine. 
Veratridine might stimulate the proliferation of putative $\mathrm{TH}^{+}$precursor cells, but this is unlikely because all $\mathrm{TH}^{+}$neuroblasts are postmitotic in the E15.5 rat brains used to prepare the cultures (Rothman et al., 1980). Furthermore, $\left[{ }^{3} \mathrm{H}\right]-$ thymidine incorporation into nuclear DNA was never observed in veratridinetreated DA neurons (data not shown). Induction of $\mathrm{TH}$ in neurons not initially committed to a catecholaminergic phenotype is also possible, although it has only been observed in non-DA areas of the brain (Du and Iacovitti, 1995). Furthermore, the number of $\mathrm{TH}^{+}$cells in veratridine-treated cultures never exceeded the number of $\mathrm{TH}^{+}$neuroblasts present just after plating. Alternatively, veratridine might simply serve to restore the expression of TH (Uezono et al., 1989) in cells in which the protein had been reduced to undetectable levels caused by suffering. This is also doubtful because delayed treatments with veratridine failed to rescue the $\mathrm{TH}^{+}$neurons already lost when the treatment with the alkaloid was initiated. In fact, two observations indicate that veratridine probably acted as a true neuroprotective factor by preventing the spontaneous demise of DA neurons: (1) apoptotic $\mathrm{TH}^{+}$neurons were present at all times in control cultures, indicating that a continuous degenerative process was ongoing; and (2) the number of these neurons was reduced to a large extent by treatment with veratridine.

\section{The effect of veratridine does not require the repression of dividing glial cells}

Several antimitotics can protect DA neurons in this culture system (Michel et al., 1997; Mourlevat et al., 2003), with a potency comparable with that of veratridine, by repressing a subpopulation of immature proliferating astrocytes responsible for the spontaneous demise of DA neurons (Mourlevat et al., 2003). Veratridine might operate via a similar mechanism. However, the alkaloid had no impact on cell proliferation, indicating that veratridine acted downstream of the level at which the toxic mechanism of glial origin intervenes.

\section{Role of T-type calcium channels in the effect of veratridine}

Survival promotion by veratridine was mimicked by $\alpha$-ScTx, a scorpion polypeptide acting as an agonist of voltage-gated $\mathrm{Na}^{+}$ channels (Jover et al., 1988), and prevented by TTX, a noncompetitive antagonist of the same channels (Catterall, 1980). This indicates that the effect of veratridine was caused by activation of inward $\mathrm{Na}^{+}$currents (Ulbricht, 1998). However, the survival rate of $\mathrm{TH}^{+}$cells in cultures treated with veratridine in the presence of TTX was identical to that in control cultures, indicating that the DA neurons that were resistant to death in the absence of treatment did not require depolarization by sodium influx for their survival.

In a previous study, we showed that depolarizing concentrations of $\mathrm{K}^{+}$can also exert strong neuroprotective effects on DA neurons if ionotropic glutamate receptors are blocked concurrently to prevent secondary excitotoxic stress (Douhou et al., 2001). Neuroprotection, in this case, resulted from a modest but significant increase in $\left[\mathrm{Ca}^{2+}\right]_{\mathrm{i}}$ via the activation of L-type voltage-gated channels (Douhou et al., 2001). A similar rise in $\left[\mathrm{Ca}^{2+}\right]_{\mathrm{i}}$ was observed after the activation of voltage-gated sodium channels by veratridine. Unexpectedly, however, both the increase in $\left[\mathrm{Ca}^{2+}\right]_{\mathrm{i}}$ and the consequent increase in DA neuronal survival were resistant to the L-type calcium channel blocker nifedipine. However, they were abolished by flunarizine, a blocker of the low-voltage activated T-type calcium channels (Santi et al., 2002), indicating that veratridine and high $\mathrm{K}^{+}$acted through distinct mechanisms. It is of interest that the inhibitory effect of flunarizine was unrelated to its ability to block D2 DA receptors (Ambrosio and Stefanini, 1991), because the neuroleptic sulpiride was inactive in the same paradigm. Consistent with the implication of T-type calcium channels, the elevation of $\left[\mathrm{Ca}^{2+}\right]_{i}$ caused by veratridine was also prevented by nickel at a low concentration that blocks this calcium channel subtype efficiently (Huguenard, 1996; Lee et al., 1999).

The fact that blockade of T-type calcium channels by flunarizine prevented neuroprotection by veratridine but not by depolarizing concentrations of $\mathrm{K}^{+}$is also in agreement with electrophysiological data showing that T-type $\mathrm{Ca}^{2+}$ currents, generated in the low range of depolarized potentials, become totally inactivated when the threshold for $\mathrm{L}$-type $\mathrm{Ca}^{2+}$ channel activation $(-40 \mathrm{mV})$ is maintained for a long period of time (Fox et al., 1987; Hammond, 2001) (i.e., in our case, in the presence of $30 \mathrm{mM} \mathrm{K}^{+}$). Conversely, this would explain why L-type calcium channel blockade was effective against $\mathrm{K}^{+}$-induced depolarization but not against veratridine.

Based on our data, one may surmise that there are at least two alternative routes for maintaining optimal neuroprotective levels of intracellular calcium that differ as a function of the depolarizing signal applied. However, the cellular mechanisms activated by the increase in cytoplasmic calcium remain elusive. It is noteworthy that smaller or greater increases in $\left[\mathrm{Ca}^{2+}\right]_{\mathrm{i}}$ were progressively less effective in rescuing DA neurons, suggesting that the range of cytoplasmic calcium levels producing optimal neuroprotection is relatively narrow, consistent with the "set-point" hypothesis originally developed for PNS neurons (Koike and Tanaka, 1991; Hegarty et al., 1997).

\section{Apamin mimics the neuroprotective effect of veratridine}

The activation of small-conductance $\mathrm{Ca}^{2+}$-activated $\mathrm{K}^{+}$channels generally decreases neuronal excitability by facilitating membrane afterhyperpolarization (Romey et al., 1984; Bond et al., 1999). We therefore hypothesized that blockade of SK channels by the bee venom toxin apamin (Stocker and Pedarzani, 2000) might mimic neuroprotection by veratridine. This was indeed the case. However, apamin was always less effective than veratridine. Furthermore, neuroprotection was improved by suboptimal concentrations of veratridine, suggesting that the bee 
toxin initiated a mechanism downstream of SK channel blockade that was indistinguishable from that of the alkaloid. Consistent with this view, both TTX and flunarizine blocked neuroprotection by apamin. The $\mathrm{Na}^{+} / \mathrm{K}^{+}$-ATPase pump inhibitor ouabain (Nelson et al., 2003) was as protective as apamin but acted via a mechanism that bypassed voltage-gated $\mathrm{Na}^{+}$channels. However, the effect of ouabain required the activation of T-type calcium channels. Overall, these results tell us that several different strategies can be used to increase the excitability of DA neurons and, thus, their survival. The crucial need for electrical stimulation may signify that the spontaneous demise of DA neurons was attributable to the isolated state of these neurons in culture, one that precluded any excitatory input. If so, this would mean that our depolarizing treatments reproduced the stabilizing effect of such input.

\section{The effect of veratridine is reproduced by, but independent of, GDNF}

GDNF is a potent survival promoting factor for DA neurons (Lin et al., 1993). In our culture model, GDNF was as potent as veratridine in rescuing DA neurons from death. Therefore, we questioned whether veratridine acted indirectly by stimulating the secretion of GDNF into the culture medium. This was doubtful because an antibody that neutralizes GDNF did not prevent the effect of the alkaloid. The possible implication of other trophic molecules acting as autocrine or paracrine factors was also excluded with treatments using conditioned media.

Because there is some evidence that GDNF can potentiate the excitability of DA neurons (Yang et al., 2001; Wang et al., 2003), we hypothesized that veratridine might simply imitate an effect of this peptide on voltage-gated channels. Ruling out this possibility, TTX and flunarizine failed to reduce neuroprotection afforded by GDNF. However, these results do not exclude that veratridine and GDNF led further downstream to the activation of common intracellular targets.

In conclusion, we have shown that GDNF and depolarizing concentrations of veratridine are equipotent in promoting the survival of cultured DA neurons. Developing DA neurons apparently lose their dependency on GDNF after postnatal day 7 (Oo et al., 2003), but exogenous GDNF can still rescue injured DA neurons in adult animals (Choi-Lundberg et al., 1997; Dauer and Przedborski, 2003). Therefore, it is reasonable to ask whether depolarizing stimuli can also influence the survival of DA neurons later in life. This is not totally excluded because SK channels and T-type $\mathrm{Ca}^{2+}$ channels, which appear to contribute to the survival of DA neurons in our culture model, are also critically involved in the low-frequency pacemaker activity (Wolfart et al., 2001; Wolfart and Roeper, 2002) that distinguishes neurons that are presumed to be vulnerable in Parkinson disease (Neuhoff et al., 2002).

\section{References}

Agid Y (1991) Parkinson's disease: pathophysiology. Lancet 337:1321-1324.

Ambrosio C, Stefanini E (1991) Interaction of flunarizine with dopamine D2 and D1 receptors. Eur J Pharmacol 197:221-223.

Bond CT, Maylie J, Adelman JP (1999) Small-conductance calciumactivated potassium channels. Ann NY Acad Sci 868:370-378.

Casper D, Mytilineou C, Blum M (1991) EGF enhances the survival of dopamine neurons in rat embryonic mesencephalon primary cell culture. J Neurosci Res 30:372-381.

Catterall WA (1980) Neurotoxins that act on voltage-sensitive sodium channels in excitable membranes. Annu Rev Pharmacol Toxicol 20:15-43.

Choi-Lundberg DL, Lin Q, Chang YN, Chiang YL, Hay CM, Mohajeri H,
Davidson BL, Bohn MC (1997) Dopaminergic neurons protected from degeneration by GDNF gene therapy. Science 275:838-841.

Dauer W, Przedborski S (2003) Parkinson's disease: mechanisms and models. Neuron 39:889-909.

DeLong MR (1990) Primate models of movement disorders of basal ganglia origin. Trends Neurosci 13:281-285.

Douhou A, Troadec JD, Ruberg M, Raisman-Vozari R, Michel PP (2001) Survival promotion of mesencephalic dopaminergic neurons by depolarizing concentrations of $\mathrm{K}+$ requires concurrent inactivation of NMDA or AMPA/kainate receptors. J Neurochem 78:163-174.

Du X, Iacovitti L (1995) Synergy between growth factors and transmitters required for catecholamine differentiation in brain neurons. J Neurosci 15:5420-5427.

Fernandez Pereira SP, Giestal DA (2000) Chronic depolarization induced by veratridine increases the survival of rat retinal ganglion cells "in vitro". Int J Dev Neurosci 18:773-780.

Fox AP, Nowycky MC, Tsien RW (1987) Single-channel recordings of three types of calcium channels in chick sensory neurones. J Physiol (Lond) 394:173-200.

Gonon FG, Buda MJ (1985) Regulation of dopamine release by impulse flow and by autoreceptors as studied by in vivo voltammetry in the rat striatum. Neuroscience 14:765-774.

Grillner P, Mercuri NB (2002) Intrinsic membrane properties and synaptic inputs regulating the firing activity of the dopamine neurons. Behav Brain Res 130:149-169.

Hammond C (2001) Subliminal voltage-gated currents of the somatodendritic membrane. In: Cellular and molecular neurobiology, pp 358373. London: Academic.

Hegarty JL, Kay AR, Green SH (1997) Trophic support of cultured spiral ganglion neurons by depolarization exceeds and is additive with that by neurotrophins or cAMP and requires elevation of $\left[\mathrm{Ca}^{2+}\right] \mathrm{i}$ within a set range. J Neurosci 17:1959-1970.

Hirsch E, Graybiel AM, Agid YA (1988) Melanized dopaminergic neurons are differentially susceptible to degeneration in Parkinson's disease. Nature 334:345-348.

Huguenard JR (1996) Low-threshold calcium currents in central nervous system neurons. Annu Rev Physiol 58:329-348.

Jover E, Massacrier A, Cau P, Martin MF, Couraud F (1988) The correlation between $\mathrm{Na}+$ channel subunits and scorpion toxin-binding sites. A study in rat brain synaptosomes and in brain neurons developing in vitro. J Biol Chem 263:1542-1548.

Kawamoto JC, Barrett JN (1986) Cryopreservation of primary neurons for tissue culture. Brain Res 384:84-93.

Kita T, Kita H, Kitai ST (1986) Electrical membrane properties of rat substantia nigra compacta neurons in an in vitro slice preparation. Brain Res 372:21-30.

Koike T, Tanaka S (1991) Evidence that nerve growth factor dependence of sympathetic neurons for survival in vitro may be determined by levels of cytoplasmic free Ca2 +. Proc Natl Acad Sci USA 88:3892-3896.

Lannuzel A, Michel PP, Caparros-Lefebvre D, Abaul J, Hocquemiller R, Ruberg M (2002) Toxicity of Annonaceae for dopaminergic neurons: potential role in atypical parkinsonism in Guadeloupe. Mov Disord 17:84-90.

Lee JH, Gomora JC, Cribbs LL, Perez-Reyes E (1999) Nickel block of three cloned T-type calcium channels: low concentrations selectively block alpha1H. Biophys J 77:3034-3042.

Lin LF, Doherty DH, Lile JD, Bektesh S, Collins F (1993) GDNF: a glial cell line-derived neurotrophic factor for midbrain dopaminergic neurons. Science 260:1130-1132.

Meder W, Fink K, Zentner J, Gothert M (1999) Calcium channels involved in $\mathrm{K}+$ - and veratridine-induced increase of cytosolic calcium concentration in human cerebral cortical synaptosomes. J Pharmacol Exp Ther 290:1126-1131.

Michel PP, Agid Y (1996) Chronic activation of the cyclic AMP signaling pathway promotes development and long-term survival of mesencephalic dopaminergic neurons. J Neurochem 67:1633-1642.

Michel PP, Dandapani BK, Knusel B, Sanchez-Ramos J, Hefti F (1990) Toxicity of 1-methyl-4-phenylpyridinium for rat dopaminergic neurons in culture: selectivity and irreversibility. J Neurochem 54:1102-1109.

Michel PP, Marien M, Ruberg M, Colpaert F, Agid Y (1999) Adenosine prevents the death of mesencephalic dopaminergic neurons by a mechanism that involves astrocytes. J Neurochem 72:2074-2082. 
Michel PP, Ruberg M, Agid Y (1997) Rescue of mesencephalic dopamine neurons by anticancer drug cytosine arabinoside. J Neurochem 69:1499-1507.

Mourlevat S, Troadec JD, Ruberg M, Michel PP (2003) Prevention of dopaminergic neuronal death by cyclic AMP in mixed neuronal/glial mesencephalic cultures requires the repression of presumptive astrocytes. Mol Pharmacol 64:578-586.

Nagamoto-Combs K, Piech KM, Best JA, Sun B, Tank AW (1997) Tyrosine hydroxylase gene promoter activity is regulated by both cyclic AMPresponsive element and AP1 sites following calcium influx. Evidence for cyclic AMP-responsive element binding protein-independent regulation. J Biol Chem 272:6051-6058.

Nelson R, Bender AM, Connaughton VP (2003) Stimulation of sodium pump restores membrane potential to neurons excited by glutamate in zebrafish distal retina. J Physiol (Lond) 549:787-800.

Neuhoff H, Neu A, Liss B, Roeper J (2002) I(h) channels contribute to the different functional properties of identified dopaminergic subpopulations in the midbrain. J Neurosci 22:1290-1302.

Obrenovitch TP, Zilkha E (1995) High extracellular potassium, and not extracellular glutamate, is required for the propagation of spreading depression. J Neurophysiol 73:2107-2114.

Oo TF, Kholodilov N, Burke RE (2003) Regulation of natural cell death in dopaminergic neurons of the substantia nigra by striatal glial cell linederived neurotrophic factor in vivo. J Neurosci 23:5141-5148.

Patil N, Cox DR, Bhat D, Faham M, Myers RM, Peterson AS (1995) A potassium channel mutation in weaver mice implicates membrane excitability in granule cell differentiation. Nat Genet 11:126-129.

Romey G, Hugues M, Schmid-Antomarchi H, Lazdunski M (1984) Apamin: a specific toxin to study a class of $\mathrm{Ca} 2+$-dependent $\mathrm{K}+$ channels. J Physiol (Paris) 79:259-264.

Rossi DJ, Oshima T, Attwell D (2000) Glutamate release in severe brain ischaemia is mainly by reversed uptake. Nature 403:316-321.

Rothman TP, Specht LA, Gershon MD, Joh TH, Teitelman G, Pickel VM, Reis DJ (1980) Catecholamine biosynthetic enzymes are expressed in replicating cells of the peripheral but not the central nervous system. Proc Natl Acad Sci USA 77:6221-6225.

Rytter A, Cronberg T, Asztely F, Nemali S, Wieloch T (2003) Mouse hippocampal organotypic tissue cultures exposed to in vitro "ischemia" show selective and delayed CA1 damage that is aggravated by glucose. J Cereb Blood Flow Metab 23:23-33.

Sanghera MK, Trulson ME, German DC (1984) Electrophysiological properties of mouse dopamine neurons: in vivo and in vitro studies. Neuroscience 12:793-801.

Santi CM, Cayabyab FS, Sutton KG, McRory JE, Mezeyova J, Hamming KS, Parker D, Stea A, Snutch TP (2002) Differential inhibition of T-type calcium channels by neuroleptics. J Neurosci 22:396-403.

Stocker M, Pedarzani P (2000) Differential distribution of three $\mathrm{Ca}(2+)$ activated $\mathrm{K}(+)$ channel subunits, SK1, SK2, and SK3, in the adult rat central nervous system. Mol Cell Neurosci 15:476-493.

Tritsch D, Chesnoy-Marchais D, Feltz A (1998) Physiologie du neurone. Paris: Doin.

Troadec JD, Marien M, Mourlevat S, Debeir T, Ruberg M, Colpaert F, Michel PP (2002) Activation of the mitogen-activated protein kinase (ERK(1/ 2)) signaling pathway by cyclic AMP potentiates the neuroprotective effect of the neurotransmitter noradrenaline on dopaminergic neurons. Mol Pharmacol 62:1043-1052.

Uezono Y, Yanagihara N, Wada A, Koda Y, Yokota K, Kobayashi H, Izumi F (1989) Veratridine-induced phosphorylation and activation of tyrosine hydroxylase, and synthesis of catecholamines in cultured bovine adrenal medullary cells. Naunyn Schmiedebergs Arch Pharmacol 339:653-659.

Ulbricht W (1998) Effects of veratridine on sodium currents and fluxes. Rev Physiol Biochem Pharmacol 133:1-54.

Wang J, Chen G, Lu B, Wu CP (2003) GDNF acutely potentiates Ca2+ channels and excitatory synaptic transmission in midbrain dopaminergic neurons. NeuroSignals 12:78-88.

Wolfart J, Neuhoff H, Franz O, Roeper J (2001) Differential expression of the small-conductance, calcium-activated potassium channel SK3 is critical for pacemaker control in dopaminergic midbrain neurons. J Neurosci 21:3443-3456.

Wolfart J, Roeper J (2002) Selective coupling of T-type calcium channels to SK potassium channels prevents intrinsic bursting in dopaminergic midbrain neurons. J Neurosci 22:3404-3413.

Yang F, Feng L, Zheng F, Johnson SW, Du J, Shen L, Wu CP, Lu B (2001) GDNF acutely modulates excitability and A-type $\mathrm{K}(+)$ channels in midbrain dopaminergic neurons. Nat Neurosci 4:1071-1078. 